\title{
In-House Validation of HPLC-MS/MS Methods for Detection and Quantification of Tetracyclines in Edible Tissues and Feathers of Broiler Chickens
}

\author{
Ekaterina V. Pokrant, ${ }^{a}$ Aldo E. Maddaleno, ${ }^{b}$ Carolina E. Araya, ${ }^{b}$ Betty V. San Martín ${ }^{b}$ and \\ Javiera Cornejo ${ }^{*, a}$
}

\author{
${ }^{a}$ Preventive Medicine Department and ${ }^{b}$ Laboratory of Veterinary Pharmacology, \\ Faculty of Veterinary and Animal Sciences, University of Chile, \\ Av. Santa Rosa 11735 La Pintana, 8820808 Santiago, Chile
}

\begin{abstract}
For the detection of tetraciclines in feathers, muscle and liver, an internal protocol was designed for in-house validation of two methods, through high performance liquid chromatography with tandem mass spectrometric (HPLC-MS/MS) techniques. This protocol was based on the recommendation of the decision 2002/657/EC from the European Community as well as the food and drug administration (FDA) VICHGL49. Limit of detection (LOD) was set at $20 \mu \mathrm{g} \mathrm{kg}^{-1}$ and the limit of quantification (LOQ) ranged from 21.5 to 24.2, 21.2 to 21.6 , and 25.0 to $27.7 \mathrm{gg} \mathrm{kg}^{-1}$ in feahers, muscle and liver samples, respectively, for all analytes. The calibrations curves show a coefficient of determination $\left(\mathrm{R}^{2}\right)$ above $0.98,0.99$ and 0.96 for feathers, muscle and liver samples, respectively. Analyte recovery ranged from 92 to $108 \%$. In conclusion, these methods can be deemed accurate and reliable, and their validation is a fundamental step to be performed in depletion studies on these matrices.
\end{abstract}

Keywords: in-house validation, HPLC-MS/MS, tetracyclines, feathers, broiler chickens

\section{Introduction}

Antimicrobials are the main therapeutic tool currently being used to control infectious pathologies from bacterial origin, thus they are used to improve the efficiency of farming systems of animals destined for human consumption. Within the poultry industry, for example, tetracyclines are widely used due to its broad spectrum activity. These antimicrobials are naturally synthesized by Streptomyces spp. and were discovered in 1948 by Benjamin Duggar. They are active against Gram positive and Gram negative bacteria, either aerobic or anaerobic, as well as Spirochaetes, Actinomyces, Rickettsia, Chlamydia, Mycoplasma and even some protozoa. Such a broad spectrum makes them especially valuable for the treatment of respiratory and digestive diseases. ${ }^{1,2}$

Chlortetracycline (CTC) and oxytetracycline (OTC) were the first members of this family and their bioavailability varies from $30 \%$ for CTC to $60 \%$ for OTC, approximately. On oral administration, they are best absorbed during fasting and worst when ingested concurrently with calcium salts or aluminium hydroxide

*e-mail: jacornej@uchile.cl as these salts exhibit chelating properties. CTC and OTC are widely distributed throughout the body and are excreted in urine and prostatic fluid. ${ }^{3}$

Anadón et al. ${ }^{4}$ determined that, following oral administration to broiler chickens, CTC has a bioavailability of $19.12 \pm 3.31,18.44 \pm 2.77$, and $17.76 \pm 1.48 \%$, after the first, fifth and final dose of the therapeutic regime. Meanwhile, following administration of a dose of $15 \mathrm{mg} \mathrm{kg}^{-1}$ to broiler chickens. Ziółkowsky et al., ${ }^{5}$ calculated a bioavailability of $76.88 \pm 12.90,92.20 \pm 10.53$, and $12.13 \pm 4.56 \%$, for intramuscular, subcutaneous and oral routes, respectively.

They also accumulate in reticuloendothelial cells from liver, spleen, bone marrow, bone, dentine and tooth enamel due to their keto-enol functional group, which allows them to chelate divalent cations. ${ }^{6,7}$ As they can also accumulate in human skin and nails, ${ }^{8}$ it can also be expected for them to bioaccumulate in other complementary structures from bird's integumentary system such as feathers, which are also built mainly from keratin. ${ }^{3}$

In this regard, some studies have shown that antimicrobials can accumulate in bird feathers at higher concentrations and for longer periods of time than in edible tissues, even after finishing the therapy and respecting withdrawal periods 
that have been established for a given formulation. San Martin et al., ${ }^{9}$ found that feathers had higher concentrations of enrofloxacin and its metabolite ciprofloxacin than muscle, liver and kidney tissues from birds that had been treated with enrofloxacin. Later on, Cornejo et al. ${ }^{10}$ found higher antimicrobial concentration levels in feather matrix than in liver and muscle samples, after the calculated withdrawal period for their formulation had elapsed. Likewise, they found that flumequine was eliminated from feathers more slowly than from other tissues. On top of that, Cornejo et al. ${ }^{11}$ showed that enrofloxacin and ciprofloxacin were transferred to feathers and that their concentrations remained higher, and for longer periods of time, than those found in edible tissues. These authors detected a $100 \mu \mathrm{g} \mathrm{kg}^{-1}$ concentration level even 9 days after treatment had elapsed. At this point in time, edible tissues had no detectable residue levels (with a detection limit of $1 \mu \mathrm{g} \mathrm{kg}^{-1}$ ).

Meanwhile, Heinrich et al. ${ }^{12}$ and Berendsen et al. ${ }^{13}$ studied bioaccumulation of ceftiofur and oxytetracycline in chicken feathers and found evidence of residues of these antimicrobials in them even when withdrawal periods were respected. More importantly, these residues were found even when drug concentrations in muscle and liver samples were either below maximum residue limits (MLR) or not detectable.

In regards to the current situation of OTC and CTC MRLs for chicken tissues, the European Union (EU) has established values of 100, 300, and $600 \mu \mathrm{g} \mathrm{kg}^{-1}$ in muscle, liver and kidney, respectively. ${ }^{14}$ Alternatively, the Codex Alimentarius has set limits of 200, 600 and $1200 \mu \mathrm{g} \mathrm{kg}^{-1}$ for muscles, liver and kidney samples, respectively. ${ }^{15}$ Meanwhile, United States of America (USA) regulations specify that allowed concentrations for those tissues are 2000, 6000 and $12000 \mu \mathrm{g} \mathrm{kg}^{-1}$ for the same tissues, respectively. ${ }^{16}$ Contrarily, for the by-products of the poultry industry like feathers, no MRLs have been determined for them.

However, based on the aforementioned information it can be concluded that antimicrobials are being transferred to feathers, and therefore represent a public health risk as they are a by-product that returns to the food chain in diets for other animals, particularly fish. ${ }^{17}$ These diets include feathers in their formulation as a low cost source of aminoacids. ${ }^{18}$

Consequently, to safeguard food safety from farm to table, antimicrobials such as tetracyclines need to be studied regarding their behavior in feathers as it relates to their concentration levels in edible tissues. However, pursuing this goal necessarily implies implementing and validating analytical methods. These methods must be able of confidently quantifying precise concentration levels of tetracycline in feather, muscle and liver samples.
However, different high resolution liquid chromatography (HPLC) methods have been reported to detect tetracyclines in edible tissues, such as muscle and liver in broiler chicken. ${ }^{19-21}$ For the feathers matrix, an analytical methodology for the detection of OTC was described by Berendsen et al..$^{13}$

Several institutions and organisms have established directives for the validation of analytical methods such as the Codex Alimentarius by FAO, VICH GL 49 by the Food and Drug Administration (FDA) ${ }^{22}$ and the 2002/657/CE decision by the European Commission. ${ }^{23}$

Based on these international guidelines, this study developed an internal protocol to validate analytical methodologies of HPLC coupled to mass spectroscopy detection (HPLC-MS/MS). The method simultaneously detects and quantifies OTC, CTC and their active metabolites 4-epi-OTC and 4-epi-CTC in feather, muscle and liver samples from broiler chicken.

\section{Experimental}

\section{Standard solutions}

Primary stock solutions for each analyte were prepared at a concentration of $1,000 \mathrm{ng} \mathrm{mL}^{-1}$ by dissolving oxytetracycline hydrochloride, chlortetracycline hydrochloride, 4-epi-oxytetracycline and 4-epi-chlortetracycline in methanol. All these analytes were manufactured by $\mathrm{Dr}$ Ehrenstorfer GmbH brand (Augsburg, Germany) and the standard had a $95.6 \%$ purity grade.

For the internal standard (IS), a primary stock solution at a concentration of $500 \mathrm{ng} \mathrm{mL}^{-1}$ was prepared by dissolving deuterated tetracycline (TC- $d_{6}$ ) in methanol. This standard was of $80 \%$ purity grade and it was manufactured by Toronto Research Chemicals (Toronto, Canada).

To spike blank samples, working solutions of OTC, CTC, 4-epi-OTC and 4-epi-CTC had a concentration of $2.5 \mathrm{ng} \mathrm{mL}-1$, while TC- $d_{6}$ working solution had a concentration of $20 \mathrm{ng} \mathrm{mL}^{-1}$. All these solutions were then stored at $-80^{\circ} \mathrm{C}$.

\section{Chemicals and reagent}

For the extraction, an ethylenediaminetetraacetic acid (EDTA)-McIlvaine buffer solution ( $\mathrm{pH} 4 \pm 0.1$ ) was prepared by mixing $500 \mathrm{~mL}$ of solution A $(14.2 \mathrm{~g}$ of disodium hydrogen phosphate dihydrate in $500 \mathrm{~mL}$ of water) with $312.5 \mathrm{~mL}$ of solution $\mathrm{B}$ (10.5 g of citric acid monohydrate in $500 \mathrm{~mL}$ of water), and then adding $3.72 \mathrm{~g}$ of EDTA to complete the solution. 
Methanol, acetonitrile and water solvents were of HPLC grade, while disodium hydrogen phosphate dihydrate, citric acid monohydrate and ethylenediaminetetraacetic acid reagents were of analytical grade quality.

Instrumentation

The equipment used for detection of the analytes was an Agilent series 1200 liquid chromatograph with a quaternary pump, an autosampler and a column oven coupled to an AB Sciex API 4000 mass triple quadrupole spectrometer. The analytical column was the Sunfire C18 $(3.5 \times 2.1 \times 150 \mathrm{~mm})$ model and it was manufactured by Waters ${ }^{\circledR}$ (Milford, Massachusetts, USA).

Chromatographic separation was performed by using a mobile phase gradient of $0.1 \%$ formic acid in water for phase A followed by $0.1 \%$ formic acid in methanol for phase B. Flow rate was set at $0.2 \mathrm{~mL} \mathrm{~min}^{-1}$, injection volume was set at $25 \mu \mathrm{L}$ and column temperature was set at $30{ }^{\circ} \mathrm{C}$. The Analyst V.1.6.2 software was used for sample integration.

\section{Experimental animals}

Experimental animals were kept in agreement with the animal welfare guidelines approved by the Bioethics Committee of the Veterinary Sciences Faculty, University of Chile, and the recommendations of the European Council Directive 2010/63. ${ }^{24}$ Additionally, animals were monitored by a veterinarian specialized in avian medicine throughout the whole experiment. The birds were sacrificed under the animal welfare rules of the European Council Directive $1099 / 2009 .^{25}$

Twenty male broiler chickens (Ross 308 genetic) were kept from 1-day-old onwards in individual cages under controlled environmental conditions $\left(25 \pm 5{ }^{\circ} \mathrm{C}\right.$ of temperature, $50-60 \%$ relative humidity), and these cages were provided with an elevated wire floor in order to prevent birds from contaminating their feathers with faeces. Additionally and prior to beginning the experiment, birds had ad libitum access to water, and nonmedicated feed whose ingredients were all analysed by HPLC-MS/MS to determine if they were free of tetracycline residues.

After slaughter, $500 \mathrm{~g}$ of muscle tissue, approximately, were sampled from each chicken, specifically from the pectoral girdle and the pelvic limb muscles. In order to have an appropriate amount of feathers and liver for sample preparation, these matrices were collected completely from each animal.

\section{Sample processing}

The muscle and liver samples were directly ground in an industrial food processor before proceeding to extract analytes from them. Feather samples though, had to be washed off to avoid contamination and then were cryogenically treated with liquid nitrogen before they could be ground. In the case of feathers, the R4 table top cutter food processor model (Robot Coupe ${ }^{\circledR}$ ) was used to grind all samples.

Implementation and optimization of analytical methodologies

The extraction procedure for feather samples was based on an analytical methodology described by Berendsen et al. ${ }^{13}$ For muscle and liver samples, extraction was based on methods described by Reveurs and Díaz, ${ }^{26}$ Khong et al..$^{27}$ and Castellari et al. ${ }^{28}$ The modifications to these methods allowed their adaption to differences arising from matrix composition and were standardized as a standardized operation procedure (SOP).

\section{Extraction procedure for feathers}

For the analysis, $5 \pm 0.05 \mathrm{~g}$ of samples were weighed in within $50 \mathrm{~mL}$ polypropylene centrifuge tubes and then fortified with oxytetracycline hydrochloride, chlortetracycline hydrochloride, 4-epi-oxytetracycline, 4-epi-chlortetracycline standards as well as with TC- $d_{6}$ as an IS.

The extraction procedure began by adding $20 \mathrm{~mL}$ of acetone and $20 \mathrm{~mL}$ of EDTA/McIlvaine to each tube. Each tube was then agitated for $30 \mathrm{~min}$ and sonicated for $5 \mathrm{~min}$ before centrifugation at $1,800 \mathrm{~g}$ for $15 \mathrm{~min}$. The resulting supernatant was filtered through a $0.22 \mu \mathrm{m}$ polyvinylidene difluoride (PVDF) membrane filter (Millipore ${ }^{\circledR}$ ). This filtrate was transferred to another $50 \mathrm{~mL}$ polypropylene tube and centrifuged again at $1,800 \mathrm{~g}$ for $5 \mathrm{~min}$. Next, $10 \mathrm{~mL}$ of EDTA/McIlvaine solution were added to this supernatant and mildly shaked by hand.

This supernatant was then passed through an OASIS HLB ${ }^{\circledR}$ solid phase extraction (SPE) column (manufactured by Waters ${ }^{\circledR}$ ) at a flux of $1 \mathrm{~mL} \mathrm{~min}{ }^{-1}$. This column had been previously conditioned with $4 \mathrm{~mL}$ of methanol, $4 \mathrm{~mL}$ of HPLC water and $4 \mathrm{~mL}$ of EDTA/McIlvaine buffer. Afterwards, a vacuum pump was used for $10 \mathrm{~min}$ to dry the column off before eluting it with $3 \mathrm{~mL}$ of methanol $\left(1 \mathrm{~mL} \mathrm{~min}^{-1}\right)$. Subsequently, each sample was evaporated under a mild nitrogen flux at a temperature of $40-50^{\circ} \mathrm{C}$ and reconstituted with $250 \mu \mathrm{L}$ of mobile phase solution of oxalic acid $0.01 \mathrm{M}$ and acetonitrile ( $\mathrm{pH} 2.2 \pm 0.2)$. 
The resulting solutions were mixed in a vortex for $5 \mathrm{~min}$, sonicated for $5 \mathrm{~min}$, and centrifuged for $5 \mathrm{~min}$ at $1,800 \mathrm{~g}$. Each centrifuged sample was then transferred to an Eppendorf tube for a final centrifugation at $1,700 \mathrm{~g}$ for $10 \mathrm{~min}$. Finally, these fully processed samples were transferred to a glass vial and ready to be analyzed chromatographically.

\section{Extraction procedure for muscle and liver}

For muscle and liver samples, a similar sequence of steps to what was described for feather samples was followed during the extraction procedure, though there were a few differences that are detailed below.

In this case, $10 \pm 0.1 \mathrm{~g}$ of muscle and liver samples were weighed in within $50 \mathrm{~mL}$ polypropylene centrifuge tubes and then fortified with oxytetracycline hydrochloride, chlortetracycline hydrochloride, 4-epi-oxytetracycline, 4-epi-chlortetracycline standards as well as with TC- $d_{6}$ as an IS.

Analyte extraction for muscle and liver tissue samples began by adding $20 \mathrm{~mL}$ of EDTA/Mcllvaine to each tube. Each sample was then homogenized in a tube shaker for $5 \mathrm{~min}$ and sonicated for $5 \mathrm{~min}$ before centrifugation at $1,800 \mathrm{~g}$ for $15 \mathrm{~min}$. The resulting supernatant was filtered through glass wool and collected in another $50 \mathrm{~mL}$ centrifuge tube. Afterwards and only in the case of the liver samples, $15 \mathrm{~mL}$ of hexane were added to all tubes containing this matrix to clean and remove fat, followed by another centrifugation at $1,800 \mathrm{~g}$ for $5 \mathrm{~min}$. For the cleaning up, the filtrate was passed through a Sep-Pak ${ }^{\circledR} \mathrm{C} 18$ (manufactured by Waters ${ }^{\circledR}$ )

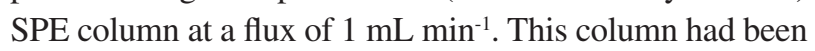
previously conditioned with $5 \mathrm{~mL}$ of HPLC water and $5 \mathrm{~mL}$ of HPLC acetonitrile. Afterwards, this column was dried off for $10 \mathrm{~min}$ in a vacuum pump and eluted with $10 \mathrm{~mL}$ of oxalic acid $0.01 \mathrm{M}$ in methanol $\left(1 \mathrm{~mL} \mathrm{~min}{ }^{-1}\right)$. Next, each sample was evaporated under a mild nitrogen flux at a temperature of $40-50{ }^{\circ} \mathrm{C}$ and reconstituted with $250 \mu \mathrm{L}$ of mobile phase solution.

The resulting solutions were agitated in a vortex for $5 \mathrm{~min}$, sonicated for $5 \mathrm{~min}$, and centrifuged for $2 \mathrm{~min}$ at $1,800 \mathrm{~g}$. The supernatant of each centrifuged sample was then transferred to a micro tube $(1.5 \mathrm{~mL})$ for a final centrifugation at $1,700 \mathrm{~g}$ for $10 \mathrm{~min}$. Finally, this fully processed samples were transferred to a glass vial and ready to be analyzed chromatographically.

\section{Validation procedure}

An internal protocol was established for in-house validation of these analytical methods. In the one hand, the assessed parameters like retention time, linearity, recovery and precision (through repeatibility and intralaboratory reproducibility) was based on the recommendations from the European Community Commission Decision EC No. 657/2002. ${ }^{23}$ On the other hand, the parameters of limits of detection (LOD) and quantification (LOQ) were based on the VICH GL49 Guidance for Industry document regarding "Validation of analytical methods used in residue depletion studies" from the FDA. ${ }^{22}$

In absence of certified reference material (CRM) for OTC, CTC, 4-epi-OTC and 4-epi-CTC in feathers, muscle and liver, the recovery performance for this method was evaluated on the basis of in-house standard materials. Samples of chicken feather, muscle and liver tissue were analyzed for OTC, CTC, 4-epi-OTC and 4-epi-CTC content to rule out contamination and certified as blank. Then they were fortified with these analytes at five different concentration levels $(20,40,60,80$ and $100 \mu \mathrm{g} \mathrm{kg}^{-1}$ ).

To assess precision for this method, its repeatability was determined by analyzing six sample sets that were fortified at three different concentration levels (20,60 and $100 \mu \mathrm{g} \mathrm{kg}^{-1}$ ) on the same day. To determine intralaboratory reproducibility, six sample sets that were fortified at three different concentration levels (20, 60 and $\left.100 \mu \mathrm{g} \mathrm{kg}^{-1}\right)$, were analyzed on different days and by different analysts.

To determine linearity of these methods, the matrix calibration curves were analyzed for five different concentration levels (20, 40, 60, 80 and $\left.100 \mu \mathrm{g} \mathrm{kg}^{-1}\right)$.

Blank feathers, muscle and liver samples from different sources were analyzed to assess both selectivity and specificity of these methods. LOD and LOQ were determined based on 20 spiked blank samples of feather, muscle and liver tissue. The criteria for selecting the LOD was to achieve a signal-to-noise ratio greater than 3:1. The LOQ was calculated as being equal to the LOD plus 1.64 times the standard deviation (SD) of the quantified concentration from 20 blank samples fortified at the LOD.

\section{Results}

Implementation and optimization of analytical methodologies

To determine if the analytical method effectively extracted OTC, CTC, 4-epi-OTC and 4-epi-CTC from the chosen biological matrices, all analytes were chromatographically detected by their masses and specific retention times $\left(\mathrm{t}_{\mathrm{R}}\right)$. At the same time, linearity $\left(\mathrm{R}^{2}>0.95\right)$ was determined by fortified calibration curves at five different and equidistant concentrations $(20,40,60,80$ and $200 \mu \mathrm{g} \mathrm{kg}^{-1}$ ). 


\section{Validation of the analytical methodologies}

The analytical methods developed in this work for feathers, muscle and liver samples were validated against an internal protocol. Results for the assessed were the following:

\section{Selectivity and specificity}

Retention time for the standards were kept constant in all six analysis and exhibited a coefficient of variation (CV) lower than five percent for all four analytes. Average retention times for OTC and its metabolite were 12.7 and $8.2 \mathrm{~min}$, respectively, while they averaged $14.6 \mathrm{~min}$ for CTC and $10.1 \mathrm{~min}$ for its metabolite. On the other hand, the TC- $d_{6}$ IS averaged $11.7 \mathrm{~min}$. To rule out the existence of interferences on the specific retention time of each analyte, 20 samples (certified to be free of residues from these antimicrobials) were analyzed and sourced separately for every matrix (feather, muscle and liver). The results showed that within the analyzed sample group there were no interfering signals on the specific retention time for these analytes, for all three biological matrices.

\section{Detection range}

The LOD was defined at $20 \mu \mathrm{g} \mathrm{kg}^{-1}$ as this concentration level provided a signal-to-noise ratio greater than $3: 1$. To validate this parameter, 20 repetitions were performed at the chosen concentration level in a fortified matrix and then their average value, standard deviation and CV (\%) were calculated. The observed variation of all repetitions for all analytes was less than $25 \%$ (Table 1).

To define the LOQ, the data for LOD calculated above was used as a starting point. To this, to the LOD value was added 1.64 times the standard deviation of all repetitions (20) in the fortified matrix at the LOD. This allowed reaching a signal-to-noise ratio greater than 10:1 for each analyte (Table 1) and, therefore, to accept these LOQ values. Figures 1 and 2 show chromatograms from standards injection and feather samples spiked with OTC, CTC, 4-epi-OTC and 4-epi-CTC standards to LOD concentration.

\section{Linearity: calibration curves}

For this study we plotted three calibration curves for five increasing and equidistant concentration levels: 20, 40, 60, 80 and $100 \mu \mathrm{g} \mathrm{kg}^{-1}$.

The $\mathrm{R}^{2}$ obtained from the calibration curves was analyzed to evaluate the linearity of the method and the individual variations of these coefficients (Table 2). The statistical values obtained for the $\mathrm{CV} \%$ are found in values below 1.1, 0.9, and $0.7 \%$ for feathers, muscle, and liver samples, respectively. The values determined that the linearity does not suffer significant variations that can affect the robustness of the analytical result.

All these calibration curves had a $\mathrm{R}^{2}$ higher than 0.95 and a CV (\%) lower than $25 \%$, as presented on Table 2, which shows the average $\mathrm{R}^{2}$ of each analyte according to matrix.

\section{Precision and recovery}

The recovery rates were calculated for every analyte based on target samples that were fortified at three concentration levels (1, 2 and 5 times the LOD). For the feather matrix all analytes exhibited recovery rates that ranged from 92 to $107 \%$, while for the muscle samples these fluctuated from 94 to $108 \%$ and in the case of liver samples they ranged from 93 to $108 \%$ (Table 3).

Table 1. Limit of detection, average concentration level, coefficient of variation of 20 repetitions on fortified samples to LOD and limit of quantification for OTC, 4-epi-OTC, CTC and 4-epi-CTC analytes, by biological matrix

\begin{tabular}{|c|c|c|c|c|c|}
\hline Biological matrix & Analyte & $\mathrm{LOD}^{\mathrm{a}} /\left(\mu \mathrm{g} \mathrm{kg}^{-1}\right)$ & $\begin{array}{l}\text { Average concentration / } \\
\left(\mu \mathrm{g} \mathrm{kg}^{-1}\right)\end{array}$ & $\mathrm{CV}^{\mathrm{b}} / \%$ & $\mathrm{LOQ}^{\mathrm{c}} /\left(\mu \mathrm{g} \mathrm{kg}^{-1}\right)$ \\
\hline \multirow[t]{4}{*}{ Feather } & OTC & 20 & 20.551 & 7.6 & 22.5 \\
\hline & 4-epi-OTC & & 14.833 & 17.40 & 24.2 \\
\hline & CTC & & 18.965 & 4.91 & 21.5 \\
\hline & 4-epi-CTC & & 22.926 & 8.03 & 22.9 \\
\hline \multirow[t]{4}{*}{ Muscle } & OTC & 20 & 21.028 & 3.62 & 21.2 \\
\hline & 4-ері-OTC & & 19.030 & 1.45 & 21.3 \\
\hline & CTC & & 20.090 & 3.96 & 21.2 \\
\hline & 4-ерi-CTC & & 20.077 & 4.81 & 21.6 \\
\hline \multirow[t]{4}{*}{ Liver } & OTC & 20 & 24.173 & 12.65 & 25.0 \\
\hline & 4-ері-OTC & & 21.064 & 20.82 & 27.2 \\
\hline & CTC & & 21.122 & 15.95 & 25.5 \\
\hline & 4-ері-СТС & & 20.075 & 23.45 & 27.7 \\
\hline
\end{tabular}

aimit of detection of the analytical methodology; ${ }^{\mathrm{a}}$ coefficient of variation; climit of quantification. 
(a)

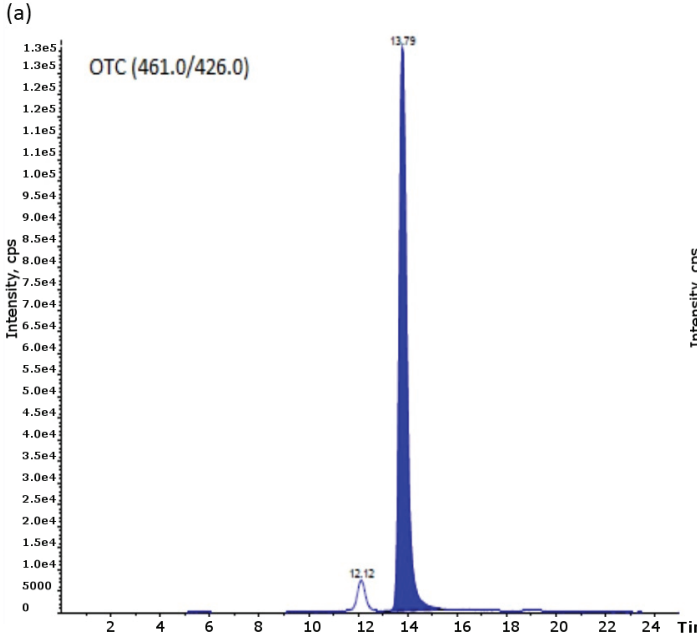

(c)

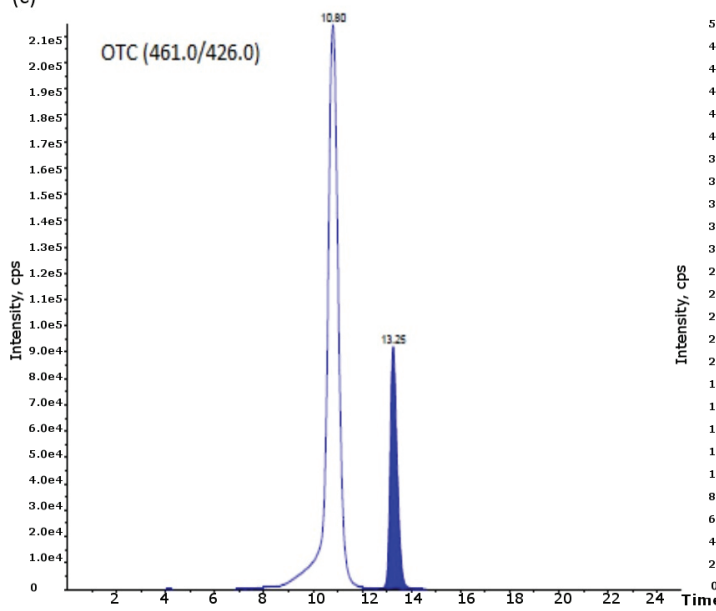

(b)

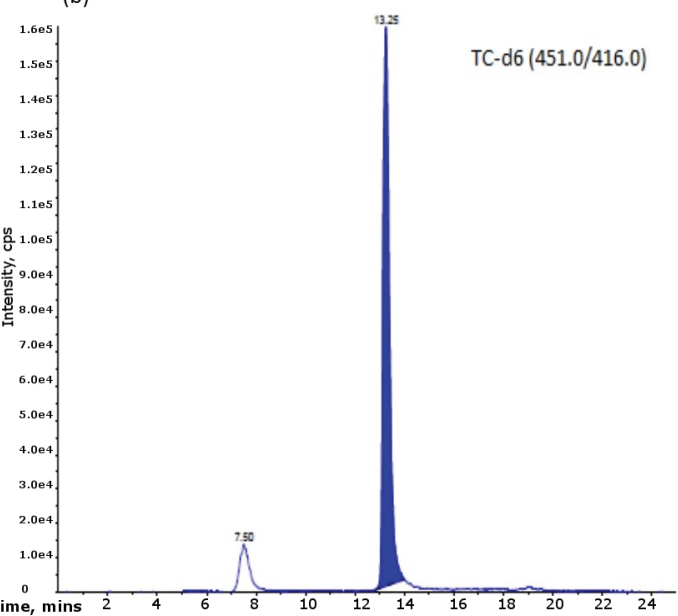

(d)

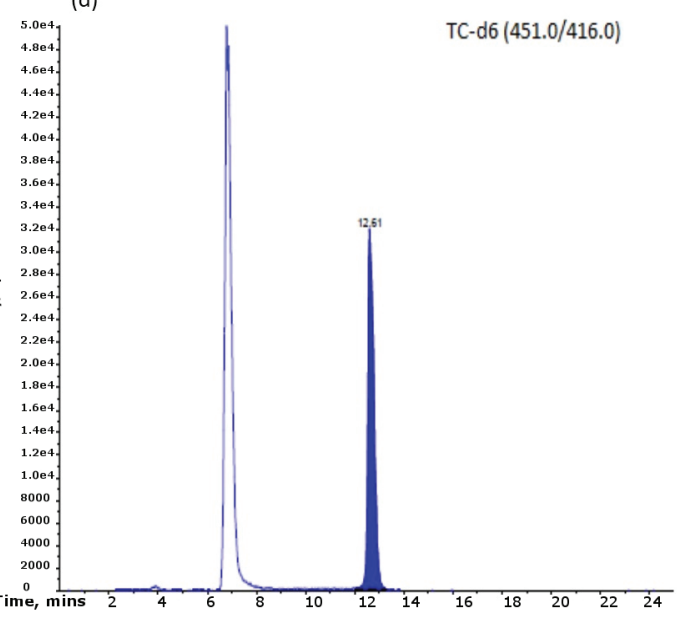

Figure 1. Chromatograms representative of (a) 6 standard injections of OTC analyte (461.0/426.0); (b) EI TC- $d_{6}$ (451.0/416.0); (c) fortified feathers samples with OTC to LOD; (d) EI TC- $d_{6}$.

The precision for the methodologies was assessed through repeatability and intralaboratory reproducibility analyses. All four analytes exhibited a similar behavior in this regard. For the fortified concentration levels of 20 and $60 \mu \mathrm{g} \mathrm{kg}^{-1}$ the intralaboratory reproducibility $\mathrm{CV}$ were less than $35 \%$. For the $100 \mu \mathrm{g} \mathrm{kg}^{-1}$ concentration level, intralaboratory reproducibility CV was $23 \%$. Meanwhile, $\mathrm{CV}$ values for repeatability were lower than those observed for intralaboratory reproducibility (Table 4).

\section{Discussion}

In 2012, Love et al., ${ }^{29}$ designed a study to build up on previous findings reported in 2007 and 2011 by San Martin et al..$^{9}$ and Cornejo et al., ${ }^{10}$ respectively, regarding the presence of antimicrobials in chicken feathers. Love et al. ${ }^{29}$ decided to sample feather meals sourced from several states in the USA. These researchers not only detected that antimicrobial drugs were present in every analyzed sample but also found multiple (from 2 to 10) antimicrobial drugs present in each sample. Among them, the most frequently found were sulfonamides, macrolides, fluoroquinolones, tetracyclines, folic acid antagonists and streptogramins. Thereby, they concluded that feathers do represent a possible source for re-entry of residues of antimicrobial drugs into the food chain and therefore, they pose a risk to public health by favoring the development of antimicrobial resistance. The latter is especially relevant as it has been shown that selection of resistant bacterial populations and the genes that confer them such resistance, is a consequence of using antimicrobial drugs at therapeutic doses as well as bacteria being exposed to much lower concentration levels. Even levels below the minimum inhibitory concentration (MIC) have been found to play an important role in this selection process. ${ }^{30}$

In this regard, Gullberg et al. ${ }^{31}$ developed highly sensitive competition experiments to determine if exposing 

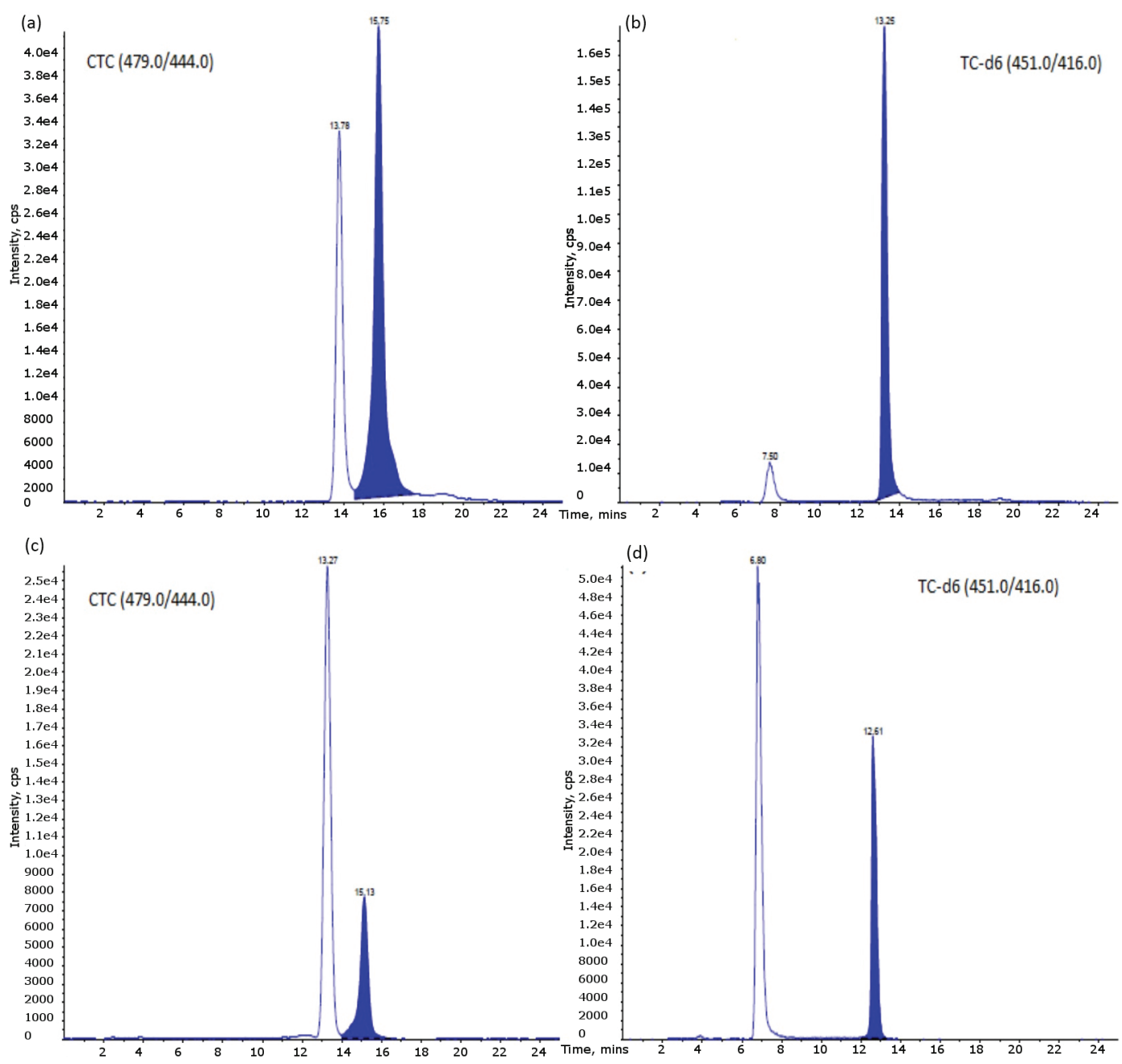

Figure 2. Chromatograms representative of (a) 6 standard injections of CTC analyte (479.0/444.0); (b) EI TC- $d_{6}$ (451.0/416.0); (c) fortified feathers samples with CTC to LOD (d) EI TC- $d_{6}$.

Table 2. Method linearity parameters for three calibration curves. $\mathrm{R}^{2}$ average and coefficient of variation for OTC, 4-epi-OTC, CTC and 4-epi-CTC analytes, by biological matrix

\begin{tabular}{lcccc}
\hline Biological matrix & Analyte & $\mathrm{R}^{2}$ average & $\mathrm{SD}^{\mathrm{b}}$ & $\mathrm{CV}^{\mathrm{c}} / \%$ \\
\hline Feather & OTC & 0.986 & 0.005 & 0.60 \\
& 4-epi-OTC & 0.985 & 0.011 & 0.97 \\
& CTC & 0.981 & 0.009 & 1.14 \\
Muscle & 4-epi-CTC & 0.985 & 0.005 & 0.56 \\
& OTC & 0.995 & 0.003 & 0.32 \\
& 4-epi-OTC & 0.997 & 0.001 & 0.19 \\
Liver & CTC & 0.991 & 0.007 & 0.72 \\
& 4-epi-CTC & 0.997 & 0.003 & 0.40 \\
& OTC & 0.966 & 0.005 & 0.60 \\
& 4-epi-OTC & 0.975 & 0.008 & 0.97 \\
& CTC & 0.960 & 0.009 & 0.90 \\
\end{tabular}

${ }^{a}$ Coefficient of determination, average from three calibration curves according analyte and matrix; ${ }^{\mathrm{b}}$ standard deviation; ${ }^{\mathrm{c}}$ coefficient of variation.

bacteria to very low concentration levels of antimicrobial drugs (below MIC) could create enrichment conditions for resistant mutant bacteria. These researchers chose several well defined mutant strains of Escherichia coli and Salmonella enterica serovar Typhimurium LT2 bacteria along with three different antimicrobial classes that are 
Table 3. Average recovery rate and coefficient of variation (CV) for 20,60 and $100 \mu \mathrm{g} \mathrm{kg}^{-1}$ concentration levels by analyte, and by biological matrix

\begin{tabular}{|c|c|c|c|c|c|c|c|}
\hline \multirow[b]{2}{*}{ Analyte } & \multirow{2}{*}{$\begin{array}{c}\text { Concentration }{ }^{\mathrm{a}} / \\
\left(\mu \mathrm{g} \mathrm{kg}^{-1}\right)\end{array}$} & \multicolumn{2}{|c|}{ Feather } & \multicolumn{2}{|c|}{ Muscle } & \multicolumn{2}{|c|}{ Liver } \\
\hline & & $\begin{array}{c}\text { Average } \\
\text { recovery / \% }\end{array}$ & $\mathrm{CV}^{\mathrm{b}} / \%$ & $\begin{array}{c}\text { Average } \\
\text { recovery / \% }\end{array}$ & $\mathrm{CV} / \%$ & $\begin{array}{c}\text { Average } \\
\text { recovery / \% }\end{array}$ & $\mathrm{CV} / \%$ \\
\hline \multirow[t]{3}{*}{ OTC } & 20 & 96 & 19 & 104 & 11 & 93 & 13 \\
\hline & 60 & 103 & 12 & 97 & 7 & 105 & 8 \\
\hline & 100 & 99 & 4 & 100 & 2 & 99 & 2 \\
\hline \multirow{3}{*}{ 4-epi-OTC } & 20 & 107 & 14 & 106 & 8 & 89 & 5 \\
\hline & 60 & 95 & 11 & 95 & 6 & 107 & 3 \\
\hline & 100 & 101 & 3 & 101 & 2 & 98 & 1 \\
\hline \multirow[t]{3}{*}{ CTC } & 20 & 92 & 15 & 108 & 8 & 89 & 16 \\
\hline & 60 & 105 & 9 & 94 & 10 & 108 & 9 \\
\hline & 100 & 98 & 3 & 101 & 3 & 98 & 3 \\
\hline \multirow[t]{3}{*}{ 4-epi-СТC } & 20 & 103 & 13 & 104 & 8 & 96 & 8 \\
\hline & 60 & 98 & 9 & 97 & 6 & 103 & 5 \\
\hline & 100 & 101 & 3 & 100 & 2 & 99 & 2 \\
\hline
\end{tabular}

${ }^{\mathrm{a}}$ Fortification concentration (levels correspond to 20,60 and $100 \mu \mathrm{g} \mathrm{kg}{ }^{-1}$ ); ${ }^{\mathrm{b}}$ coefficient of variation.

Table 4. Precision parameters: repeatability and intralaboratory reproducibility in feather, muscle and liver samples for 20,60 and $100 \mu \mathrm{g} \mathrm{kg}{ }^{-1}$ concentration levels by analyte

\begin{tabular}{|c|c|c|c|c|c|c|c|}
\hline \multirow{2}{*}{ Analyte } & \multirow{2}{*}{$\begin{array}{l}\text { Concentration }{ }^{\mathrm{a}} / \\
\left(\mu \mathrm{g} \mathrm{kg}^{-1}\right)\end{array}$} & \multicolumn{3}{|c|}{$\mathrm{CV}^{\mathrm{b}}$ of repeatability / \% } & \multicolumn{3}{|c|}{$\mathrm{CV}$ of intralaboratory reproducibility / \% } \\
\hline & & Feather & Muscle & Liver & Feather & Muscle & Liver \\
\hline \multirow[t]{3}{*}{ OTC } & 20 & 16.0 & 9.7 & 13.1 & 19.0 & 10.2 & 16.3 \\
\hline & 60 & 9.1 & 6.9 & 7.8 & 11.8 & 7.1 & 11.8 \\
\hline & 100 & 2.9 & 2.0 & 2.5 & 3.7 & 3.3 & 3.4 \\
\hline \multirow[t]{3}{*}{ 4-epi-OTC } & 20 & 13.0 & 7.9 & 15.5 & 15.6 & 10.6 & 13.7 \\
\hline & 60 & 9.0 & 5.8 & 8.5 & 9.1 & 7.0 & 9.9 \\
\hline & 100 & 2.8 & 1.7 & 2.8 & 4.5 & 2.1 & 2.8 \\
\hline \multirow[t]{3}{*}{ CTC } & 20 & 8.1 & 12.9 & 5.1 & 14.0 & 12.2 & 15.1 \\
\hline & 60 & 6.4 & 9.8 & 3.1 & 10.5 & 9.3 & 10.4 \\
\hline & 100 & 1.8 & 2.7 & 0.9 & 3.0 & 2.6 & 3.0 \\
\hline \multirow[t]{3}{*}{ 4-epi-СТC } & 20 & 8.6 & 6.6 & 8.4 & 13.0 & 8.9 & 8.6 \\
\hline & 60 & 6.6 & 4.6 & 5.2 & 9.1 & 6.5 & 7.0 \\
\hline & 100 & 1.9 & 1.4 & 1.6 & 2.7 & 1.8 & 1.9 \\
\hline
\end{tabular}

${ }^{\mathrm{a}}$ Fortification concentration (levels correspond to 20, 60 and $100 \mu \mathrm{g} \mathrm{kg}^{-1}$ ); ${ }^{\mathrm{b}}$ coefficient of variation.

greatly important in veterinary medicine (tetracyclines, fluoroquinolones and aminoglycosides). Their results show that selection of both pre-existent and newly mutant resistant bacteria occurs in extremely low concentration levels of antimicrobial drugs, even several folds below MIC for susceptible bacteria.

Additionally, Fairchild et al..$^{32}$ researched the effects of tetracyclines administration over Enterococcus spp., Escherichia coli and Campylobacter spp. bacteria that had been sourced from commercial birds. They observed on the sensitivity tests that both Enterococcus spp. and Escherichia coli were resistant to tetracyclines, in samples sourced from chicken that had been exposed to these drugs as well as from chickens that have not been exposed to them. They also noted that these bacteria possessed different resistance genes.
Consequently, we deemed important to study the behavior of tetracyclines in feathers in order to avoid transferring residues back to the food chain or even off to the environment. In the case of edible tissues of chickens for fattening, there is scientific evidence derived from studies by Anadón et al. ${ }^{4}$ in CTC and by Ziółkowski et al. ${ }^{5}$ in OTC showing that antibiotics are widely distibuted in muscle, liver and kidney of these animals.

For the HPLC-MS/MS method, the Sunfire C18 (Waters) column allowed the chromatographic separation of all analytes, including the epimers 4-epi-OTC and 4-epi-CTC, obtaining resolutions higher than 1 in each analyte. Thus, a highly selective method, fulfilling the requirements of specificity, was obtained. These same results were not performed using Symmetry C18 chromatographic columns. The use of oxalic acid modified the medium $\mathrm{pH}$ in the mobile 
phase, and also allowed to improve the chromatographic separation of the analytes, in a total reading time of $25 \mathrm{~min}$. In this analysis time all analytes were detected decisively against chromatographic interferences.

The first step in our study was to implement procedure charts for our methodologies. These procedure charts detailed all required steps to ensure chemical extraction for all analytes from the different biological matrices we worked with. We established two different SOP based on modifications from methods previously reported by Reveurs and Díaz, ${ }^{26}$ Khong et al. ${ }^{27}$ Castellari et al. ${ }^{28}$ and Berendsen et al. ${ }^{13}$ These two SOP had a few differences due to the divergent structure and composition of the biological matrices, as well as to the presence of interfering elements such as fat and protein in them.

Next, the analytical conditions were established for the three matrices. To this end, we established an internal validation protocol, based on guidelines from both the European Community and the FDA, that allowed to prove that the method was suitable for the purpose of detecting and quantifying OTC, CTC and their active metabolites in either feather, muscle or liver samples.

\section{Conclusions}

Oxytetracycline, chlortetracycline and their metabolites can be confidently and precisely detected in feather, muscle and liver samples through the implementation and validation of analytical methodologies. Validation is a fundamental step to perform in depletion studies on these three matrices, thus the present study allows to carry out further residues studies about this family of antimicrobial drugs in the above mentioned tissues.

\section{Supplementary Information}

Supplementary information is available free of charge at http://jbcs.sbq.org.br.

\section{Acknowledgments}

This work was financially supported by the Research Fund in Veterinary Sciences (FIV), 2013.

\section{References}

1. Prats, C.; El Korchi, G.; Giralt, M.; Cristòfol, C.; Peña, J.; Zorrilla, I.; Saborit, J.; Pérez, B.; J. Vet. Pharmacol. Ther. 2005, 28, 525 .

2. Cristofani, E.; Antonini, C.; Tovo, G.; Fioroni, L.; Piersanti, A.; Galarini, R.; Anal. Chim. Acta 2009, 637, 40.
3. Bragulla, H. H.; Homberger, D. G.; J. Anat. 2009, 214 , 516.

4. Anadón, A.; Gamboa, F.; Martínez, M. A.; Castellano, V.; Martínez, M.; Ares, I.; Ramos, E.; Suarez, F. H.; MartínezLarrañaga, M. R.; Food Chem. Toxicol. 2012, 50, 2714.

5. Ziółkowski, H.; Grabowski, T.; Jasiecka, A.; Zuśka-Prot, M.; Barski, D.; Jaroszewski, J. J.; Vet. J. 2016, 208, 96.

6. Patiño, N. M.; Efraín, A.; Rev. Fac. Med. U.N.A.M. 2008, 51, 29.

7. Rang, H. P.; Dale, M. M.; Ritter, J. M.; Flower, R. J.; Henderson, G.; Rang \& Dale's Pharmacology, $7^{\text {th }}$ ed.; Elsevier Churchill Livingstone: Edinburgh, Scotland, 2011.

8. Geria, A. N.; Tajirian, A. L.; Kihiczak, G.; Schwartz, R. A.; Acta Dermatovenerol. Croat. 2009, 17, 123.

9. San Martín, B.; Cornejo, J.; Iragüen, D.; Hidalgo, H.; Anadón, A.; J. Food Prot. 2007, 70, 1952.

10. Cornejo, J.; Lapierre, L.; Iragüen, D.; Pizarro, N.; Hidalgo, H.; San Martín, B.; J. Vet. Pharmacol. Ther. 2011, 34, 168.

11. Cornejo, J.; González, P.; Araya, C.; Maddaleno, A.; San Martin, B. In Residues of Veterinary Drugs in Food, vol. 2; Schilt R., ed.; Board of the EuroResidue Conferences Foundation: Egmond aan Zee, Netherlands, 2012.

12. Heinrich, K.; Chan, D.; Fussell, R. J.; Kay, J. F.; Sharman, M.; Food Addit. Contam., Part A 2013, 30, 1733.

13. Berendsen, B. J.; Bor, G.; Gerritsen, H. W.; Jansen, L. J. M.; Zuidema, T.; Food Addit. Contam. Part A. Chem. Anal. Control. Expo. Risk Assess. 2013, 30, 2102.

14. European Commission: Commission Regulation (EU) No. 37/2010 of 22 December 2009; Official Journal of the European Union, 2009, L15, p. 1. Available at https://ec.europa.eu/ health/sites/health/files/files/eudralex/vol-5/reg_2010_37/ reg_2010_37_en.pdf, accessed in October 2017.

15. Codex Alimentarius; Maximum Residue Limits (MRLs) and Risk Management Recommendations (RMRs) for Residues of Veterinary Drugs in Foods, CAC/MRL 2, 2017, p. 8. Available at http://www.fao.org/fao-who-codexalimentarius/ sh-proxy/en/?lnk=1\&url=https \%253A\%252F\%252Fwork space.fao.org $\% 252 \mathrm{Fsites} \% 252 \mathrm{Fcodex} \% 252 \mathrm{FStandards} \%$ 252FCAC\%2BMRL\%2B2\%252FMRL2e.pdf, accessed in September 2017.

16. https://www.fas.usda.gov/maximum-residue-limits-mrldatabase, accessed in August 2017.

17. Arunlertaree, C.; Moolthongnoi, C.; Environ. Nat. Resour. J. 2008, 6, 13 .

18. Divakala, K. C.; Chiba, L. I.; Kamalakar, R. B.; Rodning, S. P.; Welles, E. G.; Cummins, K. A.; Swann, J.; Cespedes, F.; Payne, R. L.; J. Anim. Sci. 2009, 87, 1270.

19. Yu, H.; Tao, Y.; Chen, D.; Wang, Y.; Yuan, Z.; Food Chem. 2011, 124, 1131.

20. Shalaby, A. R.; Salama, N. A.; Abou-Raya, S. H.; Emam, W. H.; Mehaya, F. M.; Food Chem. 2011, 124, 1660. 
21. Schneider, M. J.; Braden, S. E.; Reyes-Herrera, I.; Donoghue, D. J.; J. Chromatogr. B: Anal. Technol. Biomed. Life Sci. 2007, 846,8 .

22. U.S. Department of Health and Human Services, Food and Drug Administration, U.S. Government Printing Office: Washington, DC, 2015. Available at https://www.fda.gov/downloads/ AnimalVeterinary/GuidanceComplianceEnforcement/ GuidanceforIndustry/UCM207942.pdf, accessed in October 2017.

23. European Commission; 96/23/EC: Commission Decision of 12 August 2002; Official Journal, 2002, L 221, p. 8. Available at http://eur-lex.europa.eu/legal-content/EN/TXT/PDF/?uri=CE LEX:32002D0657\&from=EN, accessed in October 2017.

24. Directive 2010/63EU of the European Parliament and of the Council of 22 September 2010, Official Journal of the European Union, EU, 2010, L 276, p. 33. Available at http://eur-lex. europa.eu/legal-content/EN/TXT/PDF/?uri=CELEX:32010L 0063\&from=EN, accessed in October 2017.

25. European Commission: Commission Regulation No. 1099/2009 of 24 September 2009; Official Journal European Union, 2009, L 303, p. 1. Available at http://eur-lex.europa.eu/legal-content/
EN/TXT/PDF/?uri=CELEX:32009R1099\&from=EN, accessed in October 2017.

26. Reveurs, T.; Díaz, R.; Método de Determinación de Tetraciclinas en Tejido por HPLC-Diode - Array, Instituto de Salud Carlos III; Ministeria de Sanidad y Consumo, Madrid, España, 1994.

27. Khong, S. P.; Hammel, Y. A.; Guy, P. A.; Rapid Commun. Mass Spectrom. 2005, 19, 493.

28. Castellari, M.; Gratacós-Cubarsí, M.; García-Regueiro, J. A.; J. Chromatogr. A 2009, 1216, 8096.

29. Love, D. C.; Halden, R. U.; Davis, M. F.; Nachman, K. E.; Environ. Sci. Technol. 2012, 46, 5631.

30. Andersson, D. I.; Hughes, D.; Nat. Rev. Microbiol. 2014, 12, 465.

31. Gullberg, E.; Cao, S.; Berg, O. G.; Ilbäck, C.; Sandegren, L.; Hughes, D.; Andersson, D. I.; PLoS Pathog. 2011, 7, 1.

32. Fairchild, A. S.; Smith, J. L.; Idris, U.; Lu, J.; Sanchez, S.; Purvis, L. B.; Hofacre, C.; Lee, M. D.; Appl. Environ. Microbiol. 2005, 71, 5865.

Submitted: June 27, 2017

Published online: October 10, 2017 